\title{
Converses amb Cristòfol-A. Trepat
}

\author{
Entrevistat per Josep Maria Pons i Altés
}

\author{
Universitat Rovira i Virgili
}

Cristòfol-A. Trepat Carbonell és catedràtic de Didàctica de les Ciències Socials a la Universitat de Barcelona. S'ha dedicat especialment a la recerca en làmbit de la didàctica de la història i de la història de l'art, de l'ús de tecnologies bàsiques a l'aula, de l'avaluació dels resultats d'aprenentatge i d'alguns usos de les proves de correcció objectiva. Entre la seva extensa obra, podem destacar alguns llibres de referència com: Didáctica de la historia y multimedia expositiva (amb Pilar Rivero), Graó, 2010; El taller de la mirada. Una didàctica de la història de lart, Pagès Editors, 2003; El tiempo y el espacio en la didáctica de las ciencias sociales (amb Pilar Comes), Universitat de Barcelona, 1998, o Procedimientos en historia. Un punto de vista didáctico, Graó, 1995. A més a més, ha colllaborat en la confecció de nombrosos llibres de text per a tots els nivells educatius.

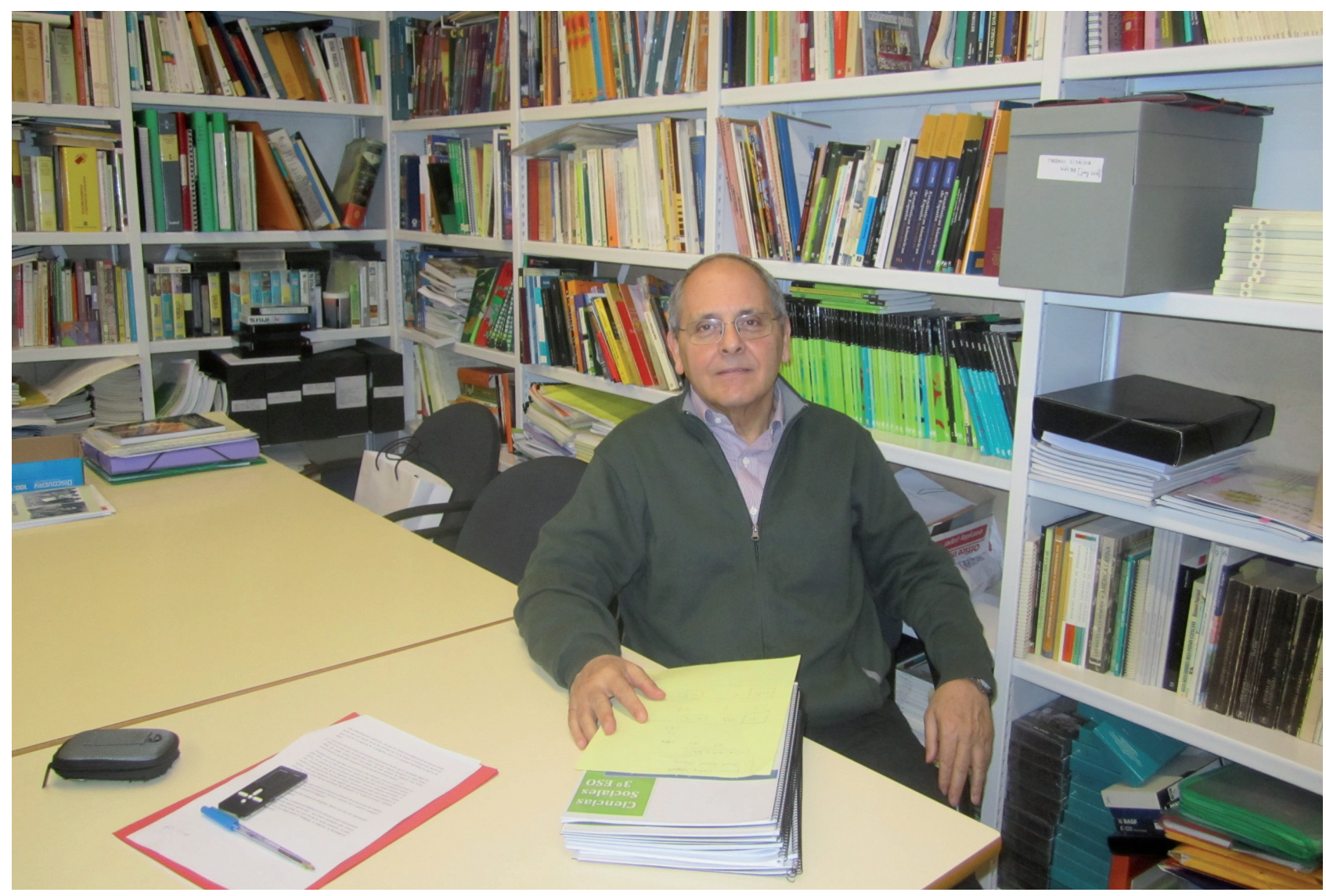


La primera pregunta és amb relació a la teva trajectòria. Tot i ser llicenciat en Història i Filologia Romànica, després la tesi ja la vas encarar a la didàctica de la història. Quin va ser el motiu de canviar el sentit de la teva recerca cap al món de la didàctica?

A veure, jo em vaig llicenciar en Història General a Filosofia i Lletres, l'especialitat que s'anomenava Història General l'any 1972, i l’any 1976 em vaig llicenciar en Filologia Romànica Catalana. Des de l'any 1968, jo impartia docència en una escola privada i a partir de l’any 1974 vaig començar a impartir docència d'història i de llengua catalana en instituts de secundària. Vaig estar en tres instituts de secundària. Aleshores, a la dècada dels vuitanta, vaig tenir l'oportunitat d'impartir una assignatura d'història de Catalunya com a professor associat a l'Escola de Mestres. Com que en aquell moment l'Escola de Mestres estava intentant adaptar-se a la reforma educativa, el departament de Didàctica de les Ciències Socials tenia molt d'interès a tenir professors de secundària nadius, per dedicar-se precisament a obrir una línia de didàctica centrada només en la secundària. En aquella època jo havia estat treballant, perquè m'ho van demanar així, al Departament d'Ensenyament sobre els currículums de l'experiència educativa que es feia amb els alumnes de catorze a setze. Vam entrar en contacte amb els que treballaven també amb els alumnes de dotze a catorze en el moment que es va començar a plantejar que la secundària obligatòria començaria als dotze anys en comptes de fer-ho als catorze. Treballant al Departament d'Ensenyament, vaig participar molt activament en el programa experimental de la reforma educativa de dotze als setze entre els anys 1984 i 1987. Va ser en entrar en aquest món, d'anar als centres educatius que experimentaven, que tota la meva activitat i la meva experiència didàctica ja comencessin a teoritzar-se i entressin, d'alguna manera, en el món de la universitat.

I aleshores, al moment de fer la tesi doctoral, vaig aprofitar allò en què estava treballant: vaig fer una avaluació de l'activitat dels quatre anys que va durar el programa experimental de la reforma educativa a base de veure què és el que s'havia après en els quatre centres que havien fet aquesta experiència, perquè només eren quatre en aquell moment, comparant els resultats amb centres docents de perfil social similar. Per tant, vaig comparar els resultats d'aprenentatge en el món de la història amb un segon curs de formació professional de la branca d'humanitats, amb un segon de BUP i amb un quart curs d'ESO. Tots tenien setze anys.

I aquest va ser el treball, analitzar com havien aplicat el currículum i quins eren els resultats que sobtenien a partir d'aquí. Perquè a mi sempre m'han interessat moltíssim els resultats concrets, perquè sense resultats penso que qualsevol teoria la podem fer especulativa ad infinitum. I aquesta és l'explicació d'aquest tomb inesperat a la meva vida a la dècada dels anys vuitanta del segle passat: passar de la pràctica habitual — vaig estar vint-i-dos anys a l'aula de secundària- cap a la recerca al món de la didàctica, sobretot a secundària.

Com bé comentes, tens molts anys d'experiència en instituts $i$ vas fer una tesi on comparaves resultats a l'inici de l'aplicació de l'ESO. Què va detectar la teva tesi doctoral? I, relacionat amb això, com valores la situació actual de l'ensenyament secundari al nostre país? Més específicament, et semblen justes les crítiques que rep l'ESO actualment a Catalunya?

Una pregunta molt llarga... Els resultats que van sortir de la meva tesi, i que no em van demanar que els publiqués enlloc, van ser que els resultats del programa experimental de la reforma educativa eren superiors de mitjana als resultats del segon curs de formació humanística de formació professional, però eren netament inferiors als que sortien de BUP, amb la qual cosa, la crítica dels professors de BUP que deien "si passem a la reforma, baixarà l'escala de coneixements" era, des del punt de vista de la tesi, correcta.

Pel que fa a l'aplicació de l'ESO a Catalunya, a la situació de l'ESO a Catalunya, el que diré ara és un judici políticament incorrecte. En teoria, com a professor universitari lligat a la didàctica, hauria de dir coses diferents, però no em dóna la gana de dir el que no és veritat, el que jo penso que no és veritat, el que jo no veig. He treballat molt amb professors de secundària $\mathrm{i}$, per tant, hi 
ha una cosa que és molt clara: el professorat de secundària està molt desmotivat i està molt cremat. És absolutament escèptic respecte de qualsevol canvi que es faci des del punt de vista oficial de la didàctica, vingui de les competències bàsiques, dels nivells de concreció o del que sigui. S'ho mira com un ase dels cops.

Ara els diuen que han d'avaluar per competències i no saben què és una competència ni els interessa gens ni mica. D’altra banda, aquest concepte de competència, que ara sembla que és la mare dels ous i que ho ha solucionat tot, penso que és un concepte que no és universal ni necessari. És a dir, que pot ser útil en determinades tasques professionals, a l'ensenyament d'idiomes, per exemple, en qüestions de formació professional, però que, per exemple, en història, literatura i filosofia no funciona. Per què? Perquè una persona que estudia literatura no té per objectiu que esdevingui un literat; una persona que estudia filosofia no té per objectiu esdevenir filòsof. És aconsellable, és ideal, és fantàstic, però no és això: és una persona que s'informa de la filosofia i coneix el pensament filosòfic, però pot no voler ser filòsof. Un professor o un alumne que estudiï història no ha d'esdevenir historiador per força. Una altra cosa és que per aprendre història faci utilitzar activitats similars al mètode de l'historiador. Això és una altra qüestió, que consti. Però un alumne que vulgui estudiar història no cal que sigui competent com un historiador. Per tant, aquesta idea de competència patina en determinats estudis humanístics. I, per tant, no solucionarà res, almenys a l'àrea en la qual m'he dedicat. $\mathrm{O}$ serà donar un nom nou a coses que ja es fan i, per tant, des d'aquest punt de vista, considero que serà irrellevant, seran més paraules que no tenen actuació sobre la realitat. Parlar de nivells competencials, que és, en definitiva, aplicar coneixements a situacions no explicades abans, el bon professor ho ha fet sempre i el qui és mal professor no ho ha fet mai i continuarà sense fer-ho.

D’altra banda, la competència no és una cosa que s'assoleixi d'un dia per l'altre ni després d'una unitat didàctica. En tot cas, és un procés que s'assoleix al cap de molt de temps. I aquest "molt de temps" es pot mirar de fer-ho al final d'una etapa, als quinze o als setze anys, però no d'un curs per l'altre. Aquesta, diguéssim, és la meva visió de les coses a partir del que m'expliquen els professors de secundària bons, amb els quals jo treballo, que em passen enquestes a classe, em passen materials, m'informen de com els ha funcionat, etc. Per tant, gent realment interessada, fins i tot en la recerca. Ja no et parlo del professor normal que compleix el seu deure i que ho deu fer molt bé, i amb aquest també hi tinc contacte, però és una visió una mica més limitada.

I al rerefons de tot el problema de la secundària, que els professors i els centres el resolen com Déu els dóna a entendre, és el problema del tractament de la diversitat. Unificar o identificar en un mateix estat el que és, per naturalesa, absolutament diferent en interessos i en capacitats és una cosa que penso que no té una solució en aquests moments.

Posaré un exemple en el camp dels idiomes. Jo recordo que quan tenia quaranta anys em van oferir una beca per anar al Japó, convidat pel govern japonès, a fer un estudi. Em van posar una única condició: que sabés anglès. En aquell moment no en sabia i, per tant, em vaig perdre el viatge al Japó. Això no em podia tornar a passar i em vaig matricular a una acadèmia on ensenyaven anglès. La primera cosa que em van fer en entrar a l'acadèmia ( $i$ jo estava motivat i pagava) va ser un examen i em van dir: "vostè va a 2 n B". I com que en aquell moment estava treballant en la reforma educativa se'm va ocórrer preguntar "per què no barregen els alumnes amb els que ja parlen anglès? Jo n’aprendria molt més". Em van dir: "home, a l'últim curs estan fent textos de Shakespeare, vostè no crec que ho comprengués d'entrada. És impossible, vostè ha d'estar a $2 \mathrm{n} \mathrm{B}$, ni a $1 \mathrm{r}$ ni a $3 \mathrm{r}$ ". Aleshores, que em diguin a mi que a $1 \mathrm{r}$ d'ESO o a $2 \mathrm{n}$ d'ESO posen trenta alumnes a una aula d'anglès on n'hi ha un que en sap una mica, perquè els seus pares n'hi han ensenyat, i un altre que no sap ni què vol dir "Merry Christmas"; està abocat al fracàs. És que és didàcticament inviable, impossible. Això que és de sentit comú, que és absolutament natural, que és una observació que és gairebé una evidència empírica, nosaltres hem cregut que no, que això és superable, posar molts alumnes junts. Com 
que això ha estat un desastre, què ha passat finalment? Doncs que tots els centres, o la immensa majoria, fan una cosa que és illlegal: posar els alumnes per nivells. No es tractava de fer això $i$, per tant, fracàs de la teoria. Llavors tornem a aquella cosa que sembla que ens agrada tant als didactes i pedagogs, que és que si la realitat no s'adiu amb la meva teoria, la que s'equivoca és la realitat, en comptes de pensar que potser ens hem equivocat en la teoria. No sé si he contestat la pregunta...

Perfectament! En aquest sentit, crec que hi ha un cert fanatisme teòric que afecta molts àmbits del coneixement, com ara també els economistes. I en el nostre cas, els efectes sobre la formació dels futurs ciutadans i dels nens són molt greus, no?

$\mathrm{Hi}$ ha una diferència amb els economistes. Tu fixa-t'hi, per exemple, que el Banc Central Europeu fa una injecció de 80.000 milions d'euros comprant deute perquè s'ha adonat que al cap de quatre anys d'austeritat anem a pitjor, no? L'economista, si s'equivoca, ho paga molt car i ha de tornar enrere. Encara recordo quan el president Mitterrand va fer una política econòmica desastrosa i va haver de canviar al cap de sis mesos perquè hi havia una gran fugida de capitals. L'economista es pot equivocar, però al cap de molt poc temps les coses, si no li funcionen, mostren que s'ha de canviar ja!

En didàctica podem fer volar coloms d'una manera indefinida perquè els resultats no s'experimenten fins al cap de deu o dotze anys. I que ara t'arribi a la universitat gent amb un vocabulari pobre i que té dificultats per expressar-se oralment i per escrit, i que no puguem apujar la nota de tall per entrar a la Facultat de Magisteri, ja demostra fins a quin punt aquesta situació ha estat un desastre.

En alguns casos és espectacular. Tu parles amb Joan Francesc Mira, per exemple, que era un catedràtic de grec de secundària i després ho va ser d'universitat, i diu: "és que jo a la universitat he hagut de donar, quan s'ha implantat la reforma educativa, coses que a cinquè de batxillerat antic estaven superadíssimes i els alumnes les aprenien molt bé". És a dir, hi ha menys riquesa de coneixement de conceptes, hi ha més pobresa en l'emissió de judicis i proposicions, hi ha més dificultats per expressar-se oralment i per escrit. Compareu, si no, un examen de la selectivitat de lèpoca que hi havia el COU amb l'examen de la selectivitat de $2 \mathrm{n}$ de batxillerat. O compareu els resultats de les proves de revàlida dels 14 anys del temps del franquisme en aspectes comparables, és a dir, en aspectes de llengües i de matemàtiques. Penseu que amb nou o deu anys la meva promoció, en castellà només, perquè el català estava prohibit, havíem de saber fer un dictat de tres línies amb un màxim de tres faltes d'ortografia, que no fossin accents, perquè si no ens suspenien. I havies de fer una divisió de dos decimals amb la prova del nou. Això amb tan sols nou i deu anys i si no, no passaves a primer de batxillerat. Hi havia un control. Vol dir que amb 9-10 anys sabíem unes determinades coses que se suposa que continuen sent útils avui dia. Hem de tenir consciència que potser hem guanyat en algunes coses, però hem de ser molt conscients dels sabers que s'estan perdent i que no es milloren.

Relacionat també amb el tema de la secundària, què et sembla el lligam entre primària i ESO? Fins a quin punt està solucionat? Continua havent-hi un trencament excessiu que es produeix en una edat complicada?

Ho conec poc, la realitat d'ara la conec poc. Jo sé que entre 6è de primària i $1 \mathrm{r}$ d'ESO els centres tenen certs contactes però, bàsicament, per indicar quin és el nivell dels alumnes que els arriben. Poca cosa més. La idea de fer un curs pont per a aquells que tinguin dificultats és una idea que no està en el pensament actual.

Jo sé, perquè això sí que ho vaig viure als anys vuitanta, que quan els alumnes feien fins a 8 è d'EGB (fins a l'actual 2n d'ESO) els mestres ja tenien des de 7è una distribució dels alumnes que anaven a formació professional o a batxillerat. Això funcionava bastant bé. De tal manera que, com que a formació professional podien fer els dos primers cursos de primer grau, i podien repetir un curs, tenien assegurat que els alumnes fins als setze anys estaven ocupats intentant aprendre alguna cosa. I amb el batxillerat, doncs igual: si es repetia primer, doncs es tenien els 


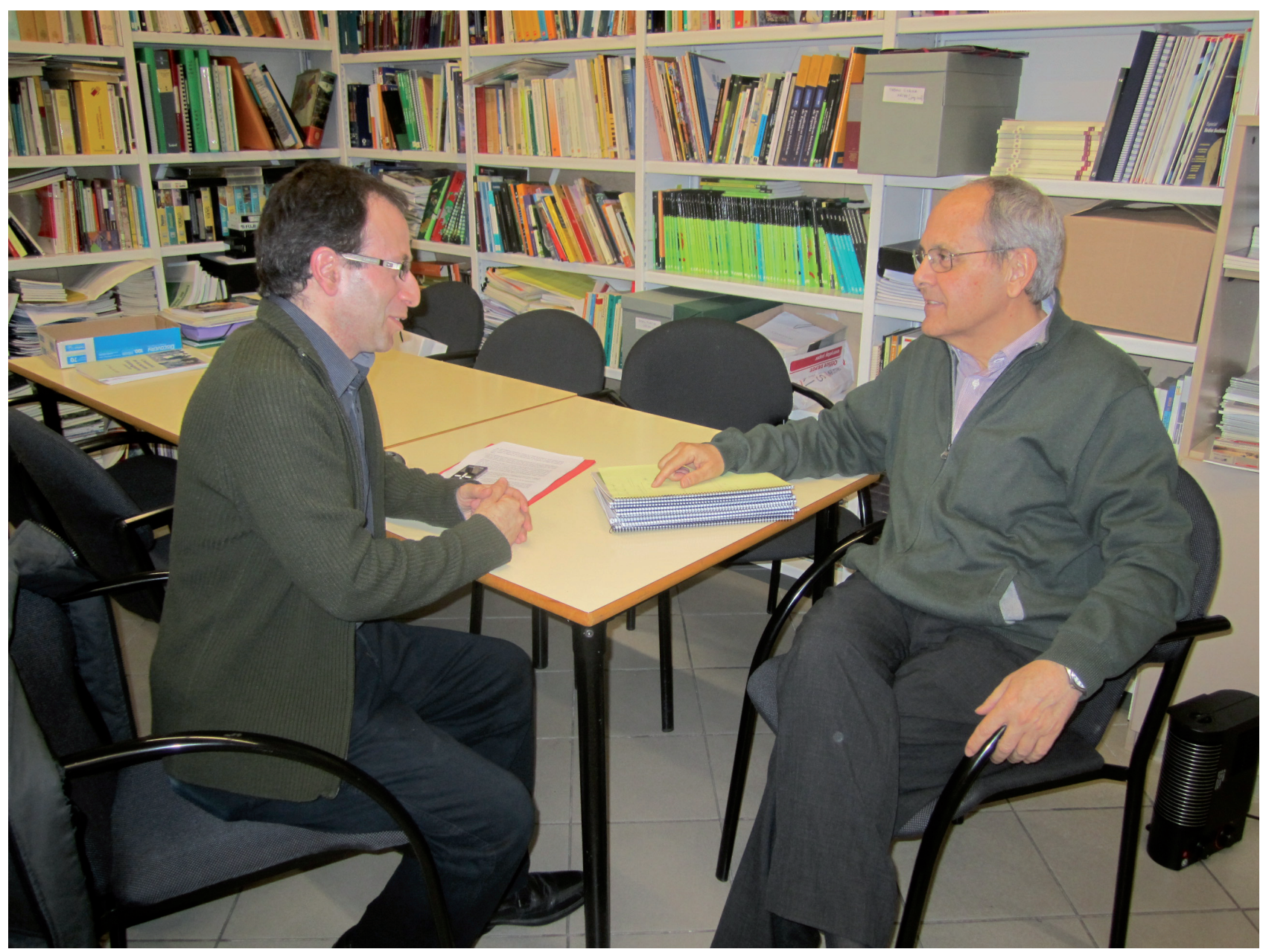

alumnes fins als setze anys i, per tant, una ocupació obligatòria en l'aprenentatge i en l'ensenyament ja existia fins als setze anys. No era per llei, però a la pràctica existia.

Després sí que vaig ser testimoni de la degradació d'alguns instituts amb la reforma, que va ser espectacular. Uns instituts que es van enderrocar, com aquell qui diu, pràcticament. No físicament, sinó des del punt de vista de la moral del professorat i de la gestió. Els dèficits que s'arrosseguen de la primària, quan arriben a la secundària tenen difícil solució. Per tant, en aquest sentit, continuo pensant en la tesi de Gregorio Luri: la clau de l'aprenentatge no és a la secundària, és a primer i segon de primària. Quan s'hi detecta algun problema, t'hi has d'abocar. Per tant, si cal invertir en educació ha de ser a primer i a segon de primària. I si cal dos o tres mestres en una aula, doncs dos o tres mestres en una aula. Però no s'ha de deixar abandonat un alumne amb dèficits que vagi passant de curs perquè és una bomba de rellotgeria que explotarà després a secundària. I a secundària no hi haurà res a fer o poc a fer. O no estem en condicions, amb la recerca actual, de poder-hi actuar per resoldre-ho.

Relacionat amb el món de primària i de secundària, ara estan molt de moda els informes PISA. Però l'àmbit de medi social, de moment, no està sent avaluat. Què penses que hauria d'avaluar-se, si és que s'ha d'avaluar, per saber el nivell dels alumnes en aquest àmbit?

El medi social, concretament la geografia i la història, és molt difícil que tingui un informe PISA que l'avaluï llevat que sigui de problemes metodològics molt genèrics i que s'haguessin assegurat que s'imparteixen a tots els països. La capacitat d'extreure informació de fonts, de fer-ne alguna valoració crítica, de contrastar-les, això s'hauria d'avisar i posar models d'exàmens i s'hauria d'indicar que tots els països, en els seus currículums, ho incloguessin. Mentre no es faci un currícu- 
lum europeu únic, cosa que no crec que passi en història i en geografia, veig impossible que PISA pugui fer un informe de ciències socials. Perquè la geografia sestudia a cada país de manera molt diferent i no cal dir la història, amb tècniques molt diferents, amb proves molt diferents d'avaluació que fan que sigui virtualment impossible fer una prova única de PISA que no sigui de tipus molt competencial o metodològic. Si no s'avisa abans que hi haurà tres temes obligatoris sobre els quals es farà una prova PISA i aquesta prova tindrà aquests models de preguntes, trobo que és virtualment impossible que es pugui fer.

Canviem les qüestions que estem tractant $i$ voldria remarcar que bona part de la teva feina també s'ha dedicat a preparar manuals escolars, $i$ has col.laborat en bastants. Com valores el nivell actual dels llibres elaborats per les nostres editorials?

Jo penso que aquí hi ha hagut un gran avenç. Els llibres que es publiquen ara, almenys per les bones editorials, són llibres amb una multiplicitat de recursos extraordinària. Si a més hi ajuntem el que aquestes bones editorials tenen com a suport als seus webs i els materials complementaris que hi ha (quaderns d'estiu, propostes d'avaluació, guies didàctiques, solucionaris de les activitats, les activitats que hi ha dins dels llibres, etc.), penso que, des del punt de vista didàctic, hem avançat moltíssim. Em refereixo a l’àmbit de les ciències socials, que és el que conec.

Una altra cosa és que, malauradament, continuem tenint uns programes i uns currículums enciclopèdics exhaustius que no permeten aprofundir. És un despropòsit descomunal el que ha fet el ministre Wert amb el segon de batxillerat: fer des d'Atapuerca fins a Rajoy en un sol curs. És inassimilable. Un llibre de text que hagi de fer des d'Atapuerca fins a Rajoy, d'història d'Espanya, ocupa cinc-centes pàgines mínim. És clar, a l'hora de dissenyar una lliçó no et pots passar de sis pàgines i no pots posar gaires activitats. Per tant, s'ha de simplificar d'una manera que resulta absolutament un despropòsit. Jo no sé què passarà amb aquests llibres, jo no em veig amb cor de fer-ne cap.
La història de l'art de batxillerat que ha proposat el ministre Wert és una cosa descomunal també. És una cosa impracticable. Ja no cal entrar en la concepció historiogràfica o política que pugui tenir: tu reparteixes el nombre de temes pel nombre d'hores de classe i et surt a tema $\mathrm{i}$ mig per hora de classe. Això ja desqualifica el projecte de currículum. Però sense arribar a aquest despropòsit descomunal, que no sé com es resoldrà, el que sí que és preocupant és l'excés de quantitat de matèria que s'ha de fer. Penso que valdria més la pena fer menys arbres que no pas tot el bosc. Vull dir que jo preferiria mil vegades un model curricular a l'anglesa que no pas a la francesa o a la hispànica. Això és una altra qüestió que condiciona el llibre de text, però en general compares els llibres de text amb els que teníem fa vint anys i crec que hem millorat d'una manera extraordinària des del punt de vista operatiu.

De vegades ens trobem mestres a qui falta preparació i que cauen en pràctiques rutinàries que a la Facultat critiquem i que després ells reprodueixen igualment a les escoles o als instituts. Com creus que podem trencar amb aquestes dinàmiques, que fa dècades que anem criticant però que encara es van reproduint?

A veure, aquí entraríem en un doble vessant. Primer, no és el mateix primària que secundària. A secundària els professors, en principi, estan més a la vora almenys d'una part de la matèria que imparteixen. En matemàtiques, els de matemàtiques només saben matemàtiques i en saben moltes. Han fet moltes matemàtiques i estan molt per sobre del nivell requerit i, per tant, es permeten tot tipus de creativitats. En ciències socials no passa tant, perquè un pot ser llicenciat en Història Contemporània i haver de donar Art a Grècia, però almenys una part la tenen i es poden espavilar.

En el cas del Magisteri passa una cosa dramàtica i és que els mestres han de donar llengua, han de donar matemàtiques, han de donar història, han de donar ciències naturals, han de donar música, etc. I la formació inicial que tenen de contingut és molt limitada, pràcticament inexistent. Hi ha alguns casos d'estudiants que vé- 
nen a la Facultat i que les últimes matemàtiques que han fet han estat a quart d'ESO i no n'han fet mai més i, a més, les van suspendre. I han pogut passar, perquè a l'ESO hi ha un altre problema: pots passar amb una assignatura suspesa. És a dir, el contingut que hi ha a l'ESO no és suficient per assegurar el coneixement que han de tenir els alumnes $i$, per tant, hi hauria una qüestió per fer en la formació, que és la que es fa en algun altre país: per ser mestre de primària, primer has de saber el contingut. Ensenyar el que un sap és difícil; ensenyar el que un no sap és impossible. De vegades, estem formant alumnes perquè ensenyin el que no saben, la qual cosa és una autèntica bestiesa. Hauríem d'agafar els currículums de primària i assegurar-nos que el mestre aquell contingut el sap, el domina. Agafem els llibres de primària de medi natural, per exemple, i examinem l'alumne que vol ser mestre d'aquests llibres de primària; ja no demano secundària, demano de primària. Agafa el de medi social i fes un examen abans d'entrar a Magisteri, no d'història i geografia de secundària i de selectivitat, de primària. Assegurem que sàpiga allò que ha de saber de primària, com a mínim. Fem un examen de matemàtiques. Fem un examen de llengua, que sigui capaç de llegir, d'escriure, de fer un dictat, d'analitzar un text, que sàpiga la gramàtica mínima que s'ha de saber. I un cop t'assegures que això ho sap, llavors l'ensenyarem a ensenyar.

Però aquests continguts no els saben, i en dono fe perquè jo he donat classes a ensenyament de mestres, a alumnes que es preparen per fer Magisteri de Primària i hem fet algun petit test de didàctica de les ciències socials, d'història i geografia bàsica, $i$ van més perduts que un pop en un garatge. Fins i tot amb una cosa tan senzilla com el primer dia de classe posar quatre imatges projectades i dir quina és de l’època antiga, medieval, moderna i contemporània, i que em diguin per què. I això no ho saben.

Què he de fer jo? Ensenyar a ensenyar una història que no saben? És un despropòsit. I això també és una cosa de sentit comú i que jo he denunciat des del primer dia que vaig començar a entrar en aquesta casa (l'escola de mestres), i no em van fer ni cas. No em puc passar durant tres mesos ensenyant història, ni que sigui al nivell de primària, perquè no és això el que se’m demana. Però, és clar, llavors perdo molt de temps. De geografia, he de reconèixer que en saben més. Però d'història... I de ciències naturals o matemàtiques, això ja no sé el que donaria de si.

Ara has comentat un problema que penso que és dramàtic, que ens hi trobem tots: la falta de domini de continguts $i \mathrm{com}$, de vegades, des d'algunes autoritats, hi ha aversió que es treballin continguts en la formació de mestres.

És una mena d’odi. Si algú parla de continguts ja és catalogat de conservador. Jo he arribat a sentir dir a una persona que ara justament té un alt càrrec en el Departament d'Ensenyament, parlant de secundària, que la culpa que els alumnes no aprenguin és dels professors perquè estan capficats a ensenyar coses en comptes d'ensenyar competències, i ensenyen coses que són obsoletes al cap de dos dies i que, per tant, no cal que les ensenyin. Jo això ho he sentit en una conferència.

I em vaig quedar... Les piràmides d'Egipte no són obsoletes, l'etapa feudal no és obsoleta. És obsoleta una aplicació de mòbil, però no és obsolet parlar de la Primera Guerra Mundial. El teorema de Pitàgores no és obsolet. El càlcul de funcions no és obsolet. Què vol dir que he d’ensenyar competències sense ensenyar continguts? És impossible. Llavors és quan entres una mica a fons en el tema competència. Què és un advocat o un metge competent? Un metge competent és el que sap aplicar els seus coneixements a una circumstància singular, que és la teva malaltia, i que et fa un bon diagnòstic i una bona teràpia. Però no és que no tingui coneixements i només tingui competències: és un metge competent perquè té coneixements i els sap aplicar. Ara nosaltres estem en una fase on volem que s'apliqui el no-res. Com es fa això? Ensenyar per competències i no ensenyar continguts és absurd.

Aquest discurs contra els continguts, que afecta tant els instituts, ha arribat en part també a la Universitat. A pesar d'això, quina valoració fas del Pla Bolonya i dels nous graus?

Per a una formació de mestres, que el grau sigui de quatre anys trobo que és un encert important. 
Des del punt de vista de l'aplicació dels graus, penso que és un pas endavant i ajuda a equiparar l'ensenyament de mestres a qualsevol altra especialitat. Que hàgim passat d'un ensenyament en el qual hi havia assignatures troncals, optatives i de lliure elecció que permetien flexibilitzar una mica el currículum a assignatures obligatòries a primer, segon i tercer fins arribar a les mencions, això ho trobo un error.

Ara, hi ha hagut aplicació del Pla Bolonya? Algú ha notat alguna cosa diferent a la universitat? El Pla Bolonya formalitza el que és informalitzable. Es pot formalitzar el nombre d'hores que un alumne ha de dedicar a l'estudi? A més, es fan seminaris i tutories com deia el Pla Bolonya? Que jo sàpiga, no. No tenim ni tan sols l'estructura arquitectònica per poder fer això. Per tant, què ha passat amb el Pla Bolonya? A la nostra Facultat tot ha continuat exactament igual. I si hi ha algun departament que ha fet alguna innovació o alguna cosa que jo ignoro, que em perdonin, m'he equivocat, però jo no he vist res.

Jo he continuat fent el mateix que feia abans, cada any amb les matèries faig noves unitats i noves coses, i he continuat fent la meva vida normal. Què tutoritzo? Treballs de final de màster, això sí. Per què? Perquè hi ha assignada una tutoria. Però a les assignatures normals que he donat amb grups de 80 no he pogut utilitzar gaire el Moodle perquè, és clar, una activitat al Moodle em suposava 160 respostes a 160 preguntes. Per descomptat, ni tutories personalitzades als treballs -és impossible tutoritzar 160 treballsni, per descomptat, seminaris. Bolonya era donar menys classes, fer seminaris i tutories i unes hores de treball individual i això no s'ha fet... que jo sàpiga. Per tant, Bolonya no s'ha aplicat, és un bluf.

Continuem amb la formació de mestres. Sovint a la universitat se la critica per viure aïllada del món real, per abusar de reflexions teòriques al marge del món escolar. Penses que aquestes crítiques són justes?

Crec que fer classes teòriques no està malament, jo sóc dels que considero que no hi ha millor element per a una bona pràctica que una bona teoria. Aleshores jo penso que, amb el sistema de pràctiques que hi ha en aquests moments, el contacte amb la realitat dels alumnes està bastant assegurat, tot i que sempre es podria fer més... I a les tutories que es fan al pràcticum és el lloc on s'hauria de trobar el contrast entre el que expliquem a classe i el que ells veuen que es fa.

Fa pocs mesos vaig llegir una entrevista a Pilar Benejam, arran de la publicació del seu últim llibre. I em va cridar l'atenció com insistia que, més enllà de la preparació tècnica i teòrica, un mestre ha de ser una persona amb interessos diversos i curiositat intel.lectual, capaç de provocar reflexions estimulants. Tu també ets una persona amb interessos diversos, fins al punt que estàs molt vinculat a l'àmbit musical. Penses que l'aposta per una especialització cada vegada més elevada, que s'està imposant a la universitat, va en contra del que demanava Pilar Benejam?

Hi ha un concepte en què jo insisteixo molt a classe i és que no hi ha mai cap formació teòrica per ser mestre o professor de secundària que et prepari per resoldre tots els problemes que puguin sortir a l'aula. I en una classe, sense tenir-ho preparat, se'm va acudir un exemple que havia

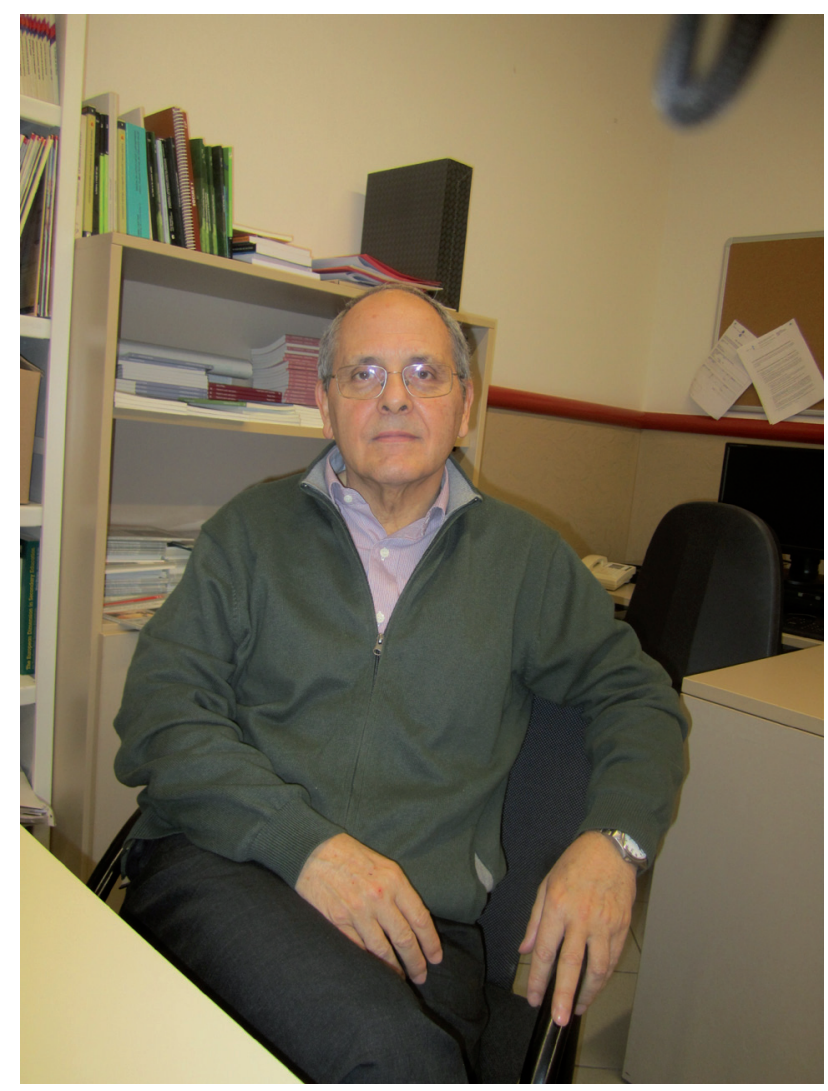


llegit en unes memòries d'un professor de secundària, on explicava que el primer dia que va entrar a classe es va trobar que els alumnes estaven jugant, estaven tirant-se un panet embolicat amb paper de plata. I diu: "A mi ningú m'havia explicat a les classes preparatòries què s'ha de fer en un cas així." I continua: "I aleshores, quan el paquet del sandvitx va passar per davant meu, el vaig agafar. Llavors el vaig començar a desembolicar. Es va fer un silenci a la classe. Llavors em vaig adonar que era un sandvitx i vaig fer una queixalada. I, llavors, més silenci a la classe. Llavors vaig preguntar: «De qui és aquest sandvitx?» «Meu.» «Qui te l'ha fet?» «La meva mare.» «Felicita la teva mare, és boníssim.»" L’hi va retornar retallant el tros que havia mossegat i va començar la classe amb ordre.

Llavors jo no puc preparar a la gent per dir què s'ha de fer quan entres $i$ et trobes que els alumnes estan jugant amb l'entrepà d'un col-lega. Hi ha una part d'artista que jo no te la puc formar. Jo et puc formar la part teòrica, però aquesta part d'artista l'has de posar tu. I per a aquesta part d'artista, si ets una persona amb interessos diversos, si fas teatre, si t’agrada la novel-la, si segueixes el cinema, sempre s'està alimentant un to vital que incideix a laula de moltes maneres: d'una manera que pot ser gairebé directa, amb exemples, amb circumstàncies, amb elements, $\mathrm{i}$ d'una manera emocional, ja que en ser una persona que presentes un perfil una mica més ric, tens més possibilitats de comprensió i d'integració de les circumstàncies que es puguin produir dins de l'aula i l'alumne t'ho pot agrair.

Per acabar, alguns col-legues opinen que, a la pràctica, part de les didàctiques específiques, i en concret de la Didàctica de les Ciències Socials, s'està apropant a una certa mena de pedagogia que abusa de les vaguetats i dels simples exercicis retòrics, fins al punt que és difícil discernir què és què. Estàs d'acord amb aquesta crítica?

A veure, la realitat és una i el que passa és que hi ha diverses mirades sobre aquesta realitat. No és el mateix la mirada d'un físic que la d'un historiador. I, precisament, d'aquestes diverses mirades és d'on surt un coneixement, sempre parcial, de la realitat. Per tant, jo penso que és diferent la
Didàctica de la Pedagogia i la de la Sociologia de l'Educació. Són mirades diferents d'un aspecte d'aquesta realitat, en aquest cas de la realitat educativa.

Sí que és veritat que he llegit, de vegades, alguns llibres que fan volar coloms, que són molt teòrics i que utilitzen un vocabulari que jo, fins i tot, de vegades no segueixo perquè no ha explicat abans què vol dir quan diu allò. Jo crec que la pedagogia és la forma raonable de coneixement del procés educatiu, en general, i la didàctica és l'art de la instrucció. Dit d'una manera com jo ho explico a l'aula, la didàctica és la teoria i la pràctica que fan possible que un contingut o una informació siguin susceptibles de ser compresos i apresos per un públic singular. Llavors, jo no faig història de l'educació ni educació comparada, ni em focalitzo en una valoració general, sinó que em focalitzo en les ciències socials. Evidentment, puc agafar aspectes de la pedagogia i puc tenir presents aspectes de la sociologia de l'educació, que són els que permetran que el futur professor o mestre vegi en què consisteix aquest context singular i quins límits i possibilitats dóna. Però jo l'he de preparar per ser capaç de presentar una informació que sigui susceptible de ser entesa, primer, i posteriorment apresa. Això és el que penso que és la didàctica.

I a la didàctica, com en totes les coses, de vegades es publiquen aspectes que són molt concrets i molt pràctics, i de vegades es fa una certa teoria que no saps ben bé a què es refereix. Això és un dels defectes històrics que tenim a la facultat. Jo sempre dic el mateix: un dels defectes que hauríem d'intentar corregir és l'abisme que hi ha entre la nostra feina en aquesta casa, en les cases universitàries en general, i la incidència real que tenim entre els que haurien o podrien aplicar-la. Sempre ho comparo: quan a la revista de medicina The Lancet surt un article on explica una tècnica per operar millor, tots els metges se la miren. I el que opera, si veu que allò és més ràpid $\mathrm{i} \mathrm{amb}$ menys cost per al pacient, ho aplica. I si no ho aplica, es trobarà que aquell que opera amb aquella tècnica que és millor li passarà al davant. Per tant, n'estan molt pendents. Quan surt la revista Science o Nature tots els científics miren líndex a veure què ha sortit de la seva especialitat. 
Malauradament, en el nostre camp, això no passa. Tu pots estar publicant articles a Íber, per exemple, i probablement no hi ha cap mestre de socials ni cap professor de secundària (o un 1 per cent) que ho llegeixi i que, si veu alguna cosa que pot millorar, ho apliqui. I això sí que és un defecte grossíssim que hauríem de saber per què passa i fins a quin punt és crític amb la nostra tasca real actual. Perquè crec que és una situació greu, i no utilitzo massa la paraula "greu" perquè ho diem tan sovint que al final la paraula "greu" no vol dir res. Els usuaris no ens fan cas i és greu. És així. Per què serveix que estiguin pagant una sèrie de gent que estigui innovant en didàctica perquè els que l'han d'aplicar els ignorin? És un problema que em plantejo seriosament amb una certa càrrega de consciència.

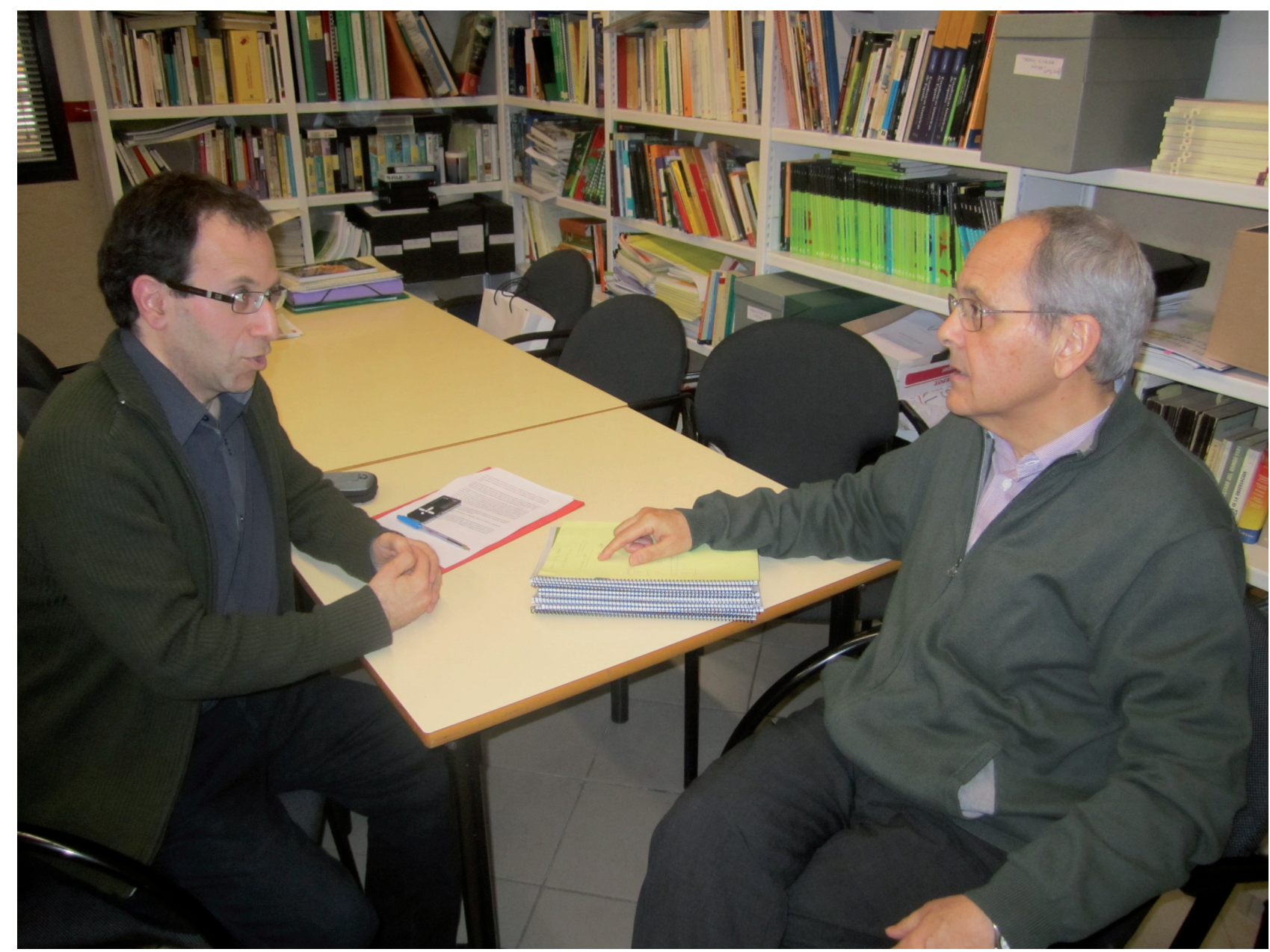

